\section{Déterminisme et prédétermination} Determinismo e predestinação

Henri Atlan 1

J'ai lu l'article H umanismo, liberdade e necessidade: compreensão dos hiatos cognitivos entre ciências da natureza e ética, de Ana M aria Coutinho Aleksandrowicz et M aria Cecília de Souza M inayo dans sa version en anglais et je le trouve bien fait. M algré ma réaction positive à l'article, je veux faire une remarque sur le temps et l'éternité spinozistes et la « prédétermination 》(dans letemps) différente de la « détermination » et du « déterminisme » sous une espèce d'éternité.

Cette remarque concerne la confusion qui s'établit souvent entre les notions de « déterminisme » et « déterminé » et celles de « prédétermination » ou de « prédeterminé » qui font penser aux notions théologiques de « prédestination » ou de « prédestiné ». Cette distinction est très importante pour une raison précise. Le déterminisme absolu de Spinoza - et celui auquel je me rallie - n'est pas une prédétermination, car il ne se situe pas dans le temps, comme si les choses étaient écrites dans le passé, avant qu'elles n'arrivent. Les choses sont déterminées « de toute éternité », c'est-à-dire de façon intemporelle, comme des vérités mathématiques. $2+2=4$ est vrai de façon intemporelle. Cette notion d'éternité chez Spinoza est très importante. Elle fait l'objet d'une définition particulière dans l'Ethique où elle est distinguée de la « durée » qui n'est pas autre chose que l'existence et du temps qui est la façon imaginée, en fait, illusoire, que nous avons de nous représenter la durée. Tout cela est une clé pour comprendre nos expériences à la fois du déterminisme et des choix. Grâce à la connaissance rationnelle, nous connaissons les choses " sous une espèce d'éternité » comme des vérités mathématiques, vraies en dehors du temps. N ous faisons en ce sens l'expérience de l'éternité, commeil le dit lui-même, ce qui ne veut pas dire l'expérience d'une vie qui continuerait indéfiniment, dans le temps, y compris après la mort. Par ailleurs, notre existence est temporelle, bien que notre expérience du temps soit ellemême inadéquate, car très imprégnée “ $d$ 'imaginé ». C'est en tant que nous nous percevons dans le temps que nous faisons l'expérience illusoire de choix libres orientés vers l'avenir. Ce point devrait être signalé, car il aide à résoudre la contradiction apparemment insurmontable entre notre connaissance du déterminisme et nos expériences de choix: elles ne se situent pas dans le même champ d'expériences par rapport au temps et à l'intemporel. Je crois l'avoir signalé moi-même, non seulement dans les "Etincelles de hasard" mais aussi dans "La science est-elle inhumaine?»

\section{A ciência entre o real épico e o ideal ético}

Science: from the epic real to the ethical ideal

\author{
Alberto Oliva 2
}
A bomba não destruirá a vida
0 homem
(tenho esperança) liquidará a bomba. (Carlos Drummond de Andrade)

Tendo F. Bacon como pregoeiro, a Era M oderna passa a privilegiar a busca de um tipo de saber que gera uma forma de poder capaz de proporcionar ao homem crescente controle sobre a natureza. 0 poder intelectual deixa de se exercer apenas sobre as consciências, pela formação de mundividências, para se estender ao domínio dos fenômenos naturais. Desaparece a necessidade de invocar forças ocultas e propósitos divinos para tentar entender o que ocorre na realidade circundante. 0 mundo se torna, como sublinha Weber, desmagicizado - um quebra-cabeça a ser decifrado apenas com os recursos da razão e da observação. Consolidado o poder explicativo e instrumental da ciência, assiste-se no século 20 ao seu crescente questionamento literário-filosófico. Os “humanistas" esposam a opinião de que a aplicação do conhecimento científico representa uma ameaça à integridade e à liberdade do homem. Literatos como Tolstoi sustentam que a ciência é desimportante porque não tem resposta para

\footnotetext{
Les auteurs remercient le Professeur $\mathrm{H}$ enri Atlan de sa lecture critique de l'article dans sa version en anglais faite par Waldéa Pereira Barcellos et Ana M aria Coutinho Aleksandrowicz et de son commentaire.

1 École des H autes Études en Sciences Sociales, Paris. H ospital H adassah, Jerusal. atlan@ehess.fr

2 Universidade Federal do Rio de Janeiro. aloliva@uol.com.br
} 